CHNO: 009

Book Title: Gender Equity in UK Sport Leadership and Governance

Editor(s): Philippa Velija, Lucy Piggott

E-ISBN: 978-1-80043-206-2

Book-meta-DOI: $10.1108 / 9781800432062$

Paperback ISBN: 978-1-80043-207-9

Subject Group:

PIT: CHP

DOI: 10.1108/978-1-80043-206-220221009

Copyright Code: $M$

Copyright-statement: Copyright (C) 2022 by Emerald Publishing Limited

Copyright-year: 2022

Copyright-holder: Emerald Publishing Limited

Publisher-name: Emerald Publishing Limited

PUBLICATION-DATE:

DAY: 27

MONTH: Jan

YEAR: 2022

Element Type: Manuscript

Figures: 0

REFERENCE STYLE : rnn

CPO RESPONSE ID :

CUSTOMER: emerald

CONVERSION: nlmbook 


\title{
Exclusionary Power and Women's Experiences of Working at the
}

\section{Football Association}

\author{
Rhea_Preston, Philippa_Velija
}

\section{Solent University, Solent University}

Abstract

This chapters adopts Rao, Stuart, and Kelleher (1999) concept of exclusionary power to understanding women's experiences of working at the Football Association (FA) which explores the ways in which power operates in multiple intersecting forms through positional power, agenda-setting power, hidden power, power of dialogue and power of conflict (Rao et al., 1999). Our research draws on interviews with women who currently or have previously worked at the English Football Association (FA). Through the framework of exclusionary power, we explore the way forms of power intersect to influence women's experiences of working within the organisation. Our research expands current knowledge of gender and gender relations in sport governance in the UK through vocalising the experiences of women working within the FA and theorising the ways in which women experience exclusionary power through intersecting, multiple and repeated everyday practices.

Keywords:_Football association; exclusionary power; gender; football; knowledge; power relations

\section{Introduction}

In this chapter we apply Rao et al.'s (1999) concept of exclusionary power to provide a qualitative analysis of the experiences of women working at the English Football Association (FA). This chapter provides a contemporary analysis of women's experiences of working in 
football at a time when there is growing awareness and publicity about sexism in the football industry. For example, the 2016 Women in Football membership survey found that $60 \%$ of women had heard sexist 'banter' or 'jokes' in the workplace and in the latest 2020 survey, 66\% of women members reported gender discrimination in the workplace (Women in Football, 2016). Documenting the experiences of women in the workplace is critical because, although the FA have complied with the 30\% gender target set by UK Sport and Sport England (2016) within A Code for Sports Governance, quotas may need to be supported by wider cultural change across the organisation and at multiple levels. In response to the new governance code and criticisms about the FA's handling of racism and harassment in the game (Velija \& Silvani, 2020), in 2018 the FA announced their equality, diversity and inclusion plan titled In Pursuit of Progress (The FA, 2018). The aim of this strategy is to develop diverse leaders across the FA to ensure the board meets the requirements of $A$ Code for Sports Governance. It prioritises four key areas: (1) the FA and its culture, (2) the England Team's support structure, (3) the game's grassroots workforce and (4) inclusion programmes across the game (The FA, 2018). More recently, in 2020, The Football Leadership Diversity Code was introduced, with the purpose of increasing the accountability for gender and ethnic diversity in football coaching and organisational structures (The FA, 2020). In this chapter we look beyond the policies and draw on data from interviews with women who have either worked at or continue to work at the FA. In doing so we seek to provide a critical analysis of how gender and power operate in the everyday experiences of those working at the FA, and how these practices may reinforce traditional gendered ways of working that may impact on future change.

\section{Theoretical Framework: Exclusionary Power}

Generating an understanding of how gender and power operates in organisations is an essential part of Rao et al.'s (1999) framework, in which they identify four key aspects of institutional arrangements that constrain gender equity. This includes individualism, balance of 
work and family, instrumentality and exclusionary power. Exclusionary power is described as operating in multiple intersecting forms through positional power, agenda-setting power, hidden power, power of dialogue and power of conflict (Rao et al., 1999). Following the work of

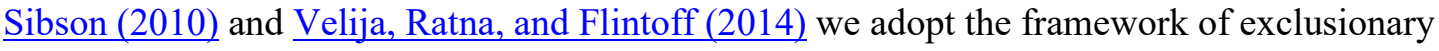
power to understand how organisational power might operate and be challenged along gender lines within the FA.

Exclusionary power is understood to derive from intersecting forms of power, the elements of which we will now discuss individually. Positional power is the authority derived from an office or title in an organisation. Rao et al. (1999) explain how this power can be both coercive and abusive when used to control or limit the power of others, but it can also be used to bring about change. Positional power can be exercised by any person in an organisation, from the CEO to front line workers, and can be used in the allocation of money, time, people, and information (Sibson, 2010). The relationship between positional power and the title of positions within organisations such as ‘Chairman' are particularly powerful and are mostly associated with the dominance of men within powerful positions ( power is also closely related to agenda-setting power, as this refers to what is and what is not on the agenda of an organisation due to its culture, values, and history (Rao et al., 1999). As some issues may never make an agenda, the key issues relating to a group may not be known, discussed, or resolved. This links to the power of dialogue, which considers how power is exercised depending on whose voices are present or privileged within an organisation.

Historically, this has been seen with the silencing of women, who are often in the minority

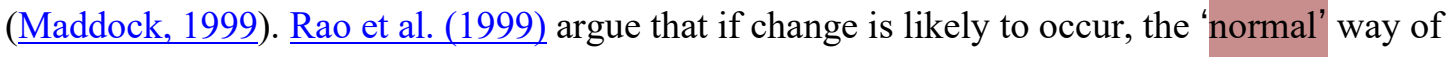
working must be challenged by using confrontational strategies to reshape an organisation (Hyles-Rainford, 2011). The final component of power within the framework is hidden power, and this refers to complex and subtle types of power. This conceptualises how power is 
exercised at the expense of others without their knowledge, through hidden or invisible networks that are accessible to groups.

Previous studies have applied Rao et al.'s (1999) framework of exclusionary power to understanding how gender power relations operate in sport organisations. Sibson (2010) utilised the concept in her study with Australian grassroots sport organisations to understand the problematic relationship between gender and power. Although the underrepresentation of men or women on the board was not an issue for either gender, the study did identify that exclusionary power was still exercised in numerous ways to limit the participation, input, and influence of its female members ( $\underline{\text { Sibson, 2010)}}$. This resulted in females often participating less in discussions and issues being 'glossed over' or ignored when raised for discussion. Despite holding positions of similar status, female employees appeared to feel that their voice did not

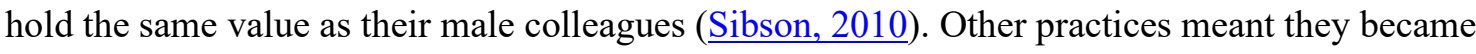
invisible and without a voice, which led to them leaving their organisation (Sibson, 2010).

Velija et al. (2014) also used the exclusionary power framework to examine power relations pre-, during and post-merger between the England and Wales Cricket Board (ECB) and the Women's Cricket Association (WCA) in 1998. They explored how gender inequities continue to impact on the management and organisation of women's cricket in England. In particular, the authors identified the different ways in which power operated pre- and post-merger to exclude women's cricket from agendas and decision making, leaving the women's game remaining marginal and invisible in the larger structure, as discussed by Nicholson in Chapter 3. In this chapter, we utilise Rao et al.'s (1999) framework of exclusionary power to understand how the FA's collection of values, history, culture, and practices can form the unquestioned "normal" way of working to preserve gender inequity within the organisation, and how different 
types of power are experienced by women working in the organisation. In the following section we provide a brief history of the FA to provide context for the cultural association between the FA and masculinity.

\section{Women, Football, and Gender}

The English Football Association was established in 1863 and was responsible for overseeing all aspects of the men's amateur and professional game in England. Despite women participating in football at this time, the FA only represented the men's game. Post-World War 1 there was an increase in women playing football, especially in charity matches that were well attended (Williams, 2016). In response to this growth the FA banned all females from FA affiliated clubs and grounds in 1921, claiming that the game of football was unsuitable for females (The FA, 2017). Although women played recreationally away from formal structures, it was not until 1969 that The Women's Football Association (WFA) was formed as the first governing body of women's football. Just two years later, in 1971, the FA council lifted the ban that forbade women from playing on the grounds of affiliated clubs, which coincided with FIFA taking control over all international football activities (Williams, 2016). In 1993 the Women's

Football Association ceased to exist, and it was agreed that power would be given to the FA with the assumption that the resources and experience of the FA would result in increased participation for girls and women.

Although the girls and women's game has grown, this has been slow and there has also been a more recent focus on addressing issues of inequity. At the time of writing, the FA have $33 \%$ representation of female board members, with an aim to increase this to $40 \%$ by the end of 2020 (The FA, 2019b). While the FA has demonstrated progress at board level, a significant gender pay gap continues to exist within the organisation (The FA, 2019a), something discussed further 
by Velija in Chapter 12. In 2017 the FA released the strategy 'Gameplan for Growth' which focused on developing opportunities for women and girls. The strategy outlines a three-year plan designed to diversify the workforce, increase participation, and change perceptions of women involved in football. In the final 2020 report evaluating the impact of strategy, the FA emphasised the success of 'Gameplan for Growth' (The FA, 2017) and stated that all targets have been met. While the implementation of targets is common in sport governance, it is an approach that has been critiqued for encouraging organisations to conduct tick-box exercises and ignoring cultural or working practices that continue to exclude women (Elling, Hovden, \& Knoppers, 20209). It is this cultural aspect of the FA that we explore in this chapter from the perspective of those women working in the organisation. In the following section we discuss the methods utilised in collecting the data for this study.

\section{Method}

The research approach for this study was qualitative and involved interviewing women who had worked or currently work in either the National FA or County FAs in England. The first author was a previous employee of the organisation and was able to contact participants through a professional network developed over a period of five years. This enabled a good rapport with the participants who trusted the researcher and was particularly important as participants were discussing both sensitive and personal matters. While working for the organisation, the first author had also experienced first-hand the gendered culture that exists at the FA and witnessed many incidents that highlighted issues of discrimination and sexism. This experience enabled a sensitive approach to the interviews but also a sense of shared understanding that aided data collection.

Interview questions were created under the five concepts of exclusionary power: positional power, agenda setting power, hidden power, power of dialogue and power of conflict. The sequence of questions was developed to include subsidiary questions to probe for further information (Gratton \& Jones, 2010, p. 177). The research involved five semi-structured in- 
depth interviews. The interviewees were aged between $25-35$ years and were all white British. This sample is reflective of the lack of BAME representation within the FA's workforce. The participants involved in this study were interviewed to investigate the way in which exclusionary power operates within the organisation, and how individual females experience the masculine culture associated with the FA on a day-to-day basis. All participants were happy to be involved on the condition their identity remained anonymous. Like Velija and Hughes' (2017) study on semi-professional female jockeys, details on each participant remain limited to ensure they are not identifiable. As such, the consent forms indicated that data would remain confidential and that no identifying information would be knowingly used. The anonymity of participants is paramount due to some individuals remaining at the organisation, so any identifiable features will be removed or adapted where possible. A theory-driven approach to analysis was developed in the form of Rao et al.'s (1999) framework of Exclusionary Power which was utilised to analyse the primary data collected via interviews. In the following section the findings are discussed and split according to several types of power and how these forms of power are operationalised.

\section{Findings}

\section{Positional Power}

Positional power is often viewed as being related to a specific position of power, but at the FA it was also related to length of service, as Lindsey discussed: 'I've noticed that the people that have been managers have been there a significant number of years, it's not somebody that started a few years ago.' This was also noted by Annie who found that the 'biggest challenge is looking at that top end, people who do what they have always done and view the game the same 
way as they always have' (Annie). The organisational structure has meant that few changes have occurred in senior management and so positional power was in the domain of men.

Positional power at the FA was also related to the dominance of groups. This was noted by Annie who found that 'leadership positions are male dominated' and Jo who explained that in her department the people making the decisions were 'men, the majority of the department were men, even the people who were women that were managers, their line managers were men.' The gender imbalance present across the workforce was particularly noticeable in the management of the organisation, as Lindsey recognised:

From a statistical standpoint, the managers were mainly made up of men. Any information put forward were taken to those manager meetings and again men would present the ideas and present the opinions $\cdots$. I think statistically there were more men there, so they were heard more.

The dominance of male leaders and their associated length of service meant that positional power could also refer to more than the title of an individual, as Katie described: 'I'm trying to piece together who I do genuinely think is making the decisions,' thus power may exist in several positions. Those who hold senior positions within the organisation are perceived to be mostly male and even those females who have progressed to hold more senior titles felt they were continuously questioned about their position in a way that male colleagues are not. Annie recalled in meetings how: "they would always go to the male first to ask the question; they would go to the guy that was there. That happens regularly.' Jo noted how ' $100 \%$ of those making decisions are male, that was the first thing mentioned to me, that the council, and the board, it is men'. This highlights how, for female employees, 'positional power' does not always translate into having a voice or 'power' to make decisions. 
Instead of feeling empowered through positional power, female employees felt pressure to demonstrate their competency and were fearful of having their contribution and knowledge questioned. This was discussed by Lindsey, who has worked at the FA for 5 years. She felt that, although she has now progressed to a more senior position, when she first started:

...there was that element of 'she's a woman', we're not going to listen......you have to prove yourself, and you have to prove yourself very quickly $\cdots$. because you realise the competition is so great around you that you can be easily replaced.

This seemed to impact on the strategies that successful women within the organisation used, which can mimic the behaviour of others in positions of power (in this case men) in the organisation:

What I noticed about the women, I didn't know any of them before so I can't comment on what they were like prior to working there, but it was almost as if they were all masculinised, like they became as equally dominant as the men. They adapted to become male (Kristina).

Kristina's observation shows how such approaches may be effective for individuals to be successful within this culture, but these approaches do not challenge the culture of an organisation or challenge how gendered and exclusionary power may operate.

\section{Agenda Setting Power}

The interview data raised examples of how agenda items were often dominated by matters that were decided by men and related to the men's game. Decisions about the agenda seemed to be most closely aligned to funding, as discussed by Katie: 'if there is not funding aligned to it, they are not going to do it.' This makes the agenda more likely to align to the men's game that has historically offered more opportunity for income generation. 
What is not discussed at meetings, and not on the agenda, is also important to consider. As Katie noted: 'the committee I'm on, we don't talk about women and girls' football. Even though we are supposed to be all of youth football, that is saved for the women and girls' committee'. The separation of, and lack of attention paid to, the girls' game, which should be discussed as part of the youth game, highlights the lack of status still aligned with it. This was further discussed by Annie who noted how in her role she tries to get the girls' and women's game onto the agenda: 'I have tried to force it on a few different committees. When I sit on the local area one, I have asked that we put women and girls on it, that is 1 out of $6^{\prime}$ [ 1 female committee member out of 6]. This reflects how what gets on the agenda is significant, and just discussing an item may reflect its importance or visibility in an organisation.

As men are more likely to be found in senior positions at the FA, they are also more likely to be involved in agenda setting. For example, when discussing who makes decisions on the agenda for meetings, Jo noted how 'I think it is the senior members and those senior members are made up of males so that's a problem in itself". These reflections led to discussions and questions about changing attitudes towards the women's game and how, without the women's game being on the agenda, a commitment to developing the women's game is not clear.

The interviewees were reflective about how the position of the women's game is viewed as different from the men's game, and this often provoked some discussion about the history and development of the game. Annie discussed how 'it is still so far behind the male game, I don't think it will ever catch up, it has so many years of oppression to overcome I don't think it will get to that point'. This is indicative of agenda setting power, which continues to position the 
women's game as different and of lesser importance. Despite policies such as the FA's 'For All' campaign - which focuses on participants having a great experience of football regardless of gender, sexuality, ethnicity, ability or disability, faith, or age - the ways in which these policies operate at a more local level are not fully understood.

The FA is dependent on small pockets of the organisation championing the women and girls' game, but the relative position of these women is important to understand. This is noted in Annie's story:

I heard from someone very high up that they created these roles so that there is a head of women's in each department, they have a monthly meeting where they come together to have a rant and a rave and discuss the things happening, but then go back off to their departments for another month.

Having a 'head of women's' in each department can be problematic as this might continue to position the women's game as being separate to 'football' and the rest of the organisation. This could create a situation where the women's game is considered separate and something women deal with, as opposed to being a key strategy and development within football that all have responsibility for.

\section{Power of Dialogue}

The power of dialogue can have a direct impact on agenda setting power, as those who are not heard have little power to set the agenda to facilitate change. This has led some to suggest that change is happening only because of $A$ Code for Sports Governance and not because they believe diversifying the organisation adds any value:

A senior FA male openly said 'we've got two females - tick, we've got a BAME - tick, we've got a this - tick' $\cdots .$. The FA are more open to having a diverse board because they must do something, 
they have to have someone of a certain gender to hit a mark on the Governance Code without seeing the benefits (Katie).

Katie, who now holds a more senior position than when she started at the FA suggested that marginal voices are not heard: 'I don't know if its intended or just a felt impact of, certainly when I came into my role at the FA, apart from those that I knew, everyone else was a battle to get them to listen.' This is similar to the findings of Parker (2019), who identified in her study on challenging institutionalised practices within national governing bodies that women working in male environments were not able to influence decisions or be heard. This is indicative of the power of dialogue, whereby women perceived their voices to hold less value than their male colleagues. These situations impact on women's ability with an organisation to be heard and enact change.

The power of dialogue can also refer to ways in which people in organisations communicate. For the women interviewed they all recognised that 'banter' played a key role by giving more power to specific voices. Most of the women interviewed stated they had often been made to feel uncomfortable by comments made towards themselves or others:

Office banter and using those two terms is an absolute understatement. Banter in any job is to just joke freely about things. Banter within football is to heights you cannot imagine (Lindsey).

The role of banter in the organisation made some women feel like they had no option but to join in to ensure they did not become a target. Lindsey noted, 'I had to become like one of the boys, so it would stop and that's exactly what happened'. Whilst some recognised that banter could build relationships, there was recognition that it was also an 'escape goat' for colleagues to make inappropriate and unprofessional remarks, demonstrating the way in which power through dialogue is disseminated across the organisation. Katie explained: 
At the FA I've been dealt a few banter cards which aren't banter, they're not jokes, they're not funny.

The thing with banter and jokes is that your view of jokes is different to mine (Katie).

The role of banter in the organisation reflects a form of power that operates to exclude some people. The emphasis on banter as fun and part of the culture seeks to position those that question banter as unable to take a 'joke'. Banter can be used as a mechanism for positioning some people on the inside and others on the outside. This creates an environment which, according to Lindsey, is very 'cliquey, it's like a pack $\cdots$ if you weren't part of the pack, you would feel isolated'. Banter within the organisational culture of the FA had become normalised: If I heard that on the street somewhere, I would think that's horrific, I can't believe you said that, but because it's within football and they have that locker room banter it spills into the office. It's like if you're not part of it if you don't go along with it (Lindsey).

The culture of banter becomes something the women working at the FA have to manage, as Jo explains, "it is quite brash, loud, to the point, it can be rude, cringey. Erm there is a lot, day to

day'. For some people working in this environment becomes untenable and they can no longer stay in the organisation:

You see it all the time when banters gone too far people get upset and $\cdots$ then they are classed as weak and they can't take the banter. You see it all the time where there's a couple of people who are sick to death of it and just walk away (Jo).

There were examples of more extreme and inappropriate behaviour, that also was often not questioned: 
I was showing an older gentleman to where the drinks were and again we passed the toilets and he said 'do you fancy it?', '. I I awkwardly laughed, I didn't know what to say and maybe I should of said something (Lindsey).

Lindsey's choice not to question or challenge the person is not common, as many female employees are reluctant to challenge this through fear of potential consequences (Women in Football, 2016). This is one incident that demonstrates the way in which positional power may prevent issues from being challenged or addressed. While most employees knew the process of making a complaint and felt that issues of a sexist nature would be dealt with seriously, Katie noted that 'there is so much riding on making a complaint and challenging someone'. The culture of the organisation impacts on those working at the FA to prevent dialogue. That is, the power of dialogue can impact on peoples' experiences and contribute to a culture in which complaining or speaking up is very difficult, and people leave the organisation.

\section{Power of Conflict}

$\underline{\text { Rao et al. (1999) }}$ argue that for change to occur, the 'normal' way of working must be challenged by using confrontational strategies and using the power of conflict. This can have impact because 'there's too many stereotypes, fixed mind sets or thoughts that have to be broken and that aren't being broken because people don't want them to. It's self-preserving rather than thinking about the bigger picture' (Katie). The stereotypes that Katie refers to are often held by those on senior boards and councils, as Katie went on to say:

People are doing what they've always done because its comfortable, it's normal and it has not been challenged. People have to see that people not like them can add value before they believe it. 
Several employees identified strategies and tactics they adopted to fit within the organisation. Lindsey suggested that 'it was either become like one of the rest or quickly find that you will probably struggle in an environment like that if you didn't adapt quickly'. In a similar study, Sotiriadou and De Haan (2019) identified that women felt the need to adjust their behaviour to fit in with the culture of the organisation and often behaved like men to be accepted.

Many of the women interviewed in this study acknowledged that they changed swiftly upon starting their employment with the FA and this was a coping mechanism to get by. For those who had worked at other organisations prior to the FA, there was a noticeable difference in culture. Power then is not just about current operation, but how behaviours become normalised in ways that may marginalise others. This was noted by Katie: "it is the culture that needs

addressing'. However, adopting a position where the women also communicate and use banter can exemplify the problem and reinforce the way in which power operates within the organisation:

I just think if we're moving towards gender equality and diversity in the workplace then if you normalise it and try to be something you're not then you're not getting what you want, you're making it worse (Katie).

As Katie noted, there are more women working in the women's side of the game because an underrepresentation of women in leadership positions in men's sports has led women to seek opportunity in the women's game. It was raised that people may be willing to accept advice from females on the female game, but this was not the case in the male game: 
You are in a leadership position for the female game, but you can't do it in the male game, even

though technically you have exactly the same skills. But the perception is that is good enough for the women's game but not the male (Annie).

The women interviewed as part of this study who held senior positions within the organisation continue to push for change for women's football, and in doing so they often challenged traditional mindsets. This did however mean that some women were viewed as a 'nuisance '- trying to break down walls' (Annie). Katie highlighted that the environment impacted on this as the FA is 'a male dominated environment that people are put out by females being in leadership positions, even if it's an unconscious bias type thing'. Katie acknowledges that such biases are not always intentional but that within an organisation the norm is often perpetuated when most of the senior team are 'the same' thus there can be a perception that male leaders are the norm.

\section{Hidden Power}

Hidden power refers to power that is exercised at the expense of others without their knowledge. Hidden power appeared to present itself through normalising behaviour, with many suggesting that female employees often changed in the organisation, but this was accepted as 'normal' and brushed off as 'just football':

Whether or not you intend to change or not the environment changes you completely. But in doing so I became a stronger character, but I'm very different now and I totally recognise that my personality and myself has changed (Lindsey).

In Walker and Bopp (2011) they found that men are afforded greater opportunities in both men's and women's sports and they refer to the concept of the 'glass wall' to explain how the 
underrepresentation of women in senior management and leadership roles has become institutionalised. A lack of females in senior positions results in some employees accepting that career progression and promotion is more likely for their male counterparts. While both Katie and Lindsey had achieved a promotion while working at the organisation for some time, they could not recall many other females being promoted recently:

I'm trying to think if there is someone who has been employed or promoted in the last few months and I can only think of two females $\cdots$. I think you can become numb to it (Katie).

Hidden power operates because cultural assumptions mean that women assume men to have more right within the organisation for promotion. Female employees were often dismissive of their male colleagues being promoted ahead of them and defended them by suggesting that there are 'a bigger pool of males that fit that criteria' (Kristina). This concurs with similar studies by Velija et al. (2014) who explored how roles in sport organisations utilise existing networks and found there is a 'taken-for-granted' assumption that men have more knowledge and experience and are more likely to be appointed to these roles. The unquestioned privilege and positional power of men is particularly evident in senior leadership. Ryan and Dickson (2018) argue, however, that the gender leadership problem is not just about the underrepresentation of women, but the dominance of men and the valued forms of masculinity which are often considered synonymous with dominant forms of leadership.

\section{Conclusion}

In this chapter we have applied the framework of exclusionary power to identify how gendered power operates within the FA through the experiences of the women who work in the organisation at various levels. We utilise the concept of exclusionary power to illustrate the way in which different and intersecting forms of power can create an exclusionary space for women. This is significant as we can highlight the everyday experiences of women at the FA to 
demonstrate the ways in which different forms of power impacts on women's everyday gendered working experiences.

Through the framework of exclusionary power, it became clear that positional power remains dominated by males in senior and decision-making positions. Interestingly, we found that in addition to access to positional power being gendered (i.e. fewer women being recruited into leadership positions), the effect of positional power is also gendered. Women in this study did not experience the same influence from obtaining positions of power compared to their male counterparts and felt compelled to prove themselves once in position. We were also able to explore how agenda setting power is influenced by what is funded and a recognition that the agenda may ignore girls' and women's sport. Furthermore, in considering the power of dialogue on women's experiences of working at the FA, we found that banter was a specific way of communicating in the organisation which seeks to reinforce gendered power and exclude individuals.

Our research expands current knowledge of gender and gender relations in sport governance in the UK through vocalising the experiences of women working within the FA and theorising the ways in which women experience exclusionary power through intersecting, multiple and repeated everyday practices. The framework of exclusionary power identifies different types of power relations and how they intersect within the organisation and helps to explain how dominant gender power relations are reproduced and why it is so difficult to enact change. We would suggest that the framework could be used by organisations to explore the multiple and intersecting forms of power that create exclusionary power in their organisations. In doing so, organisations may be able to recognise the complexity of power and how it is operationalised. This is significant because the recent focus for sports organisations has been on equalling numbers and bringing more females into senior positions on the assumption that simply bringing more females into the organisation will give them a voice (Sibson, 2010). As a theoretical framework exclusionary power does have some limitations and researchers should 
be aware of other intersecting forms of power, such as the power of networks, that may not neatly fit into the themes of the framework. The framework could therefore be strengthened and extended by considering other gendered forms of power within organisations. In summarising this chapter we suggest that more is needed to be done to address the culture of sport organisations to consider how forms of power can be identified, disrupted, and challenged by identifying the gendered practices that exclude women and other marginal voices.

References

$\mathrm{Ah}$ Elling and Hovden, 2020_Elling, A.,Hovden, J.\& Knoppers, A. (2019). Gender diversity in European sport governance._Oxon: Routledge. Refstyled Gratton and Jones, 2010_Gratton 2 C.\& Jones, _. (2010). Research methods for sports studies (pp. 1

Hyles-Rainford, 2011_Hyles-Rainford,_._(2011). Bridging the opportunity gap: Leadership, social difference, career and education. Bloomington, IN: IUniverse. Refstyled Maddock, 1999.Maddock, S. (1999). Challenging women: Gender, culture and organization (pp. 101). London: Sage. Refstyled Rao and Stuart, 1999_Rao_A._Stuart_R.\&Kelleher,D.(1999).Gender at work: Organizational change for equality.West Hartford, CT: Kumarian Press. Refstyled Ryan and Dickson, 2018_Ryan,_, \& Dickson, G. (2018). The invisible norm: An exploration of the intersections of sport, gender and leadership._Leadership, 14(3),329_346. doi: $10.1177 / 1742715016674864$ Refstyled Shaw and Hoeber, 2003 Shaw _S. \& Hoeber, L. (2003). "A strong man is direct and a direct woman is a bitch': Gender discourses and their influence on employment roles in sport 
organizations. Journal of Sport Management, 17(4), 347-375.

doi: $10.1123 /$ jsm.17.4.347 Refstyled

Sibson, 2010 Sibson, R. (2010). I was banging my head against a brick wall: Exclusionary power and the gendering of sport organizations. Journal of Sport Management,2010(24),379= 399. Refstyled

Sotiriadou and De Haan, 2019 Sotiriadou, P \& \& De Haan,D. (2019). Women and leadership: Advancing gender equity policies in sport leadership through sport governance. International Journal of Sport Policy and Politics, 11(3), 365-383. doi:10.1080/19406940.2019.1577902 Refstyled

The FA, 2017.The FA. (2017). The history of women's football in England. Retrieved from http://www.thefa.com/womens-girls-football/historyRefstyled

The FA, 2019a The FA. (2019a). One year on, our equality, diversity and inclusion plan is on track. Retrieved from_https://www.thefa.com/news/2019/oct/01/in-pursuit-of-progress-oneyear-report-011019Refstyled

The FA, 2019b The FA. (2019b). The FA structure. Retrieved from https://www.thefa.com/about-football-association/who-we-are/structureRefstyled The FA, 2020 The FA. (2020). The FA's football leadership diversity code launched. Retrieved from https://www.thefa.com/news/2020/oct/27/football-leadership-diversity-code-launched271020 Refstyled

UK Sport and England, 2016_UK Sport and Sport England.(2016). A code for sports governance. Retrieved from_https://www.uksport.gov.uk/resources/governance-codeRefstyled Velija et al., 2014_Velija_P._Ratna_A._\& Flintoff_A. (2014).Exclusionary power in sports organisations: The merger between the Women's Cricket Association and the England and 
Wales Cricket Board_International Review for the Sociology of Sport, 49(2),211_226. doi: $10.1177 / 1012690212455962$ Refstyled

Velija and Silvani, 2020_Velija_. P.\& Silvani____(2020).Print media narratives of bullying and harassment at the football association: A case study of Eniola Aluko_Journal of Sport \& Social Issues. doi: $10.1177 / 0193723520958342$ Refstyled

Walker and Bopp, 2011_Walker, N.\& Bopp,T.,(2011). The underrepresentation of women in the male dominated sport workplace: Perspectives of female coaches, Journal of Workplace Rights, 15(1)47_64. doi:10.2190/WR.15.1.d

Women in Football, 2016.Women in Football.(2016). Women in football: Survey 2016.

Retrieved from https://www.womeninfootball.co.uk/resources/women-in-football-2016-surveyanalysis.htmlRefstyled

QC

TUD QC 